
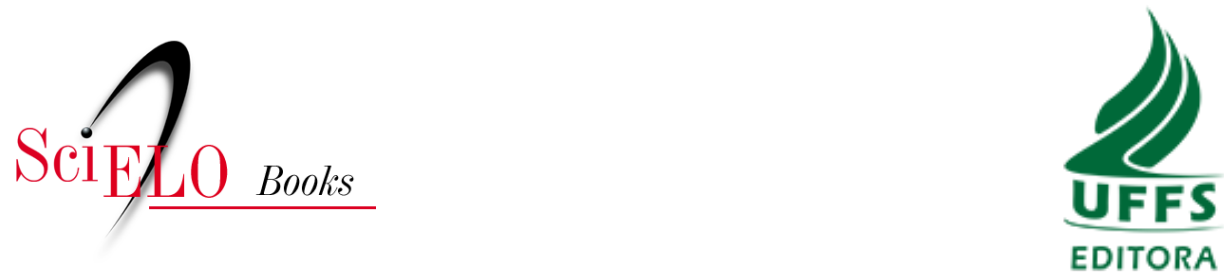

Parte V - Desenvolvimento e novas tecnologias produtivas e sociais

\title{
Capítulo 4 - Análise de um modelo de gestão cooperativista e como suas estratégias contribuíram com a sustentabilidade dos associados: o caso Cooperoque
}

\section{Roberto Ajala \\ Raquel Borghetti \\ Edio Polacinski \\ Luciana Scherer \\ Edson Bolzan \\ SciELO Books / SciELO Livros / SciELO Libros}

AJALA, R., BORGHETTI, R., POLACINSKI, E., SCHERER, L., and BOLZAN, E. Análise de um modelo de gestão cooperativista e como suas estratégias contribuíram com a sustentabilidade dos associados: o caso Cooperoque. In: ROTTA, E., LAGO, I.C., JUSTEN, A.F., and SANTOS, M., eds. Conhecimento em rede: desenvolvimento, cooperação e integração regional em território de fronteira - Rede CIDIR: 10 anos [online]. Chapecó, SC: Editora UFFS, 2019, pp. 309326. ISBN: 978-65-5019-011-8. https://doi.org/10.7476/9786586545432.0019.

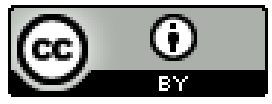

All the contents of this work, except where otherwise noted, is licensed under a Creative Commons Attribution 4.0 International license.

Todo o conteúdo deste trabalho, exceto quando houver ressalva, é publicado sob a licença Creative Commons Atribição 4.0.

Todo el contenido de esta obra, excepto donde se indique lo contrario, está bajo licencia de la licencia Creative Commons Reconocimento 4.0. 


\title{
ANÁLISE DE UM MODELO DE GESTÃO COOPERATIVISTA E COMO SUAS ESTRATÉGIAS CONTRIBUÍRAM COM A SUSTENTABILIDADE DOS ASSOCIADOS: O CASO COOPEROQUE
}

\author{
Roberto Ajala ${ }^{1}$ \\ Raquel Borghetti ${ }^{2}$ \\ Edio Polacinski ${ }^{3}$ \\ Luciana Scherer ${ }^{4}$ \\ Edson Bolzan ${ }^{5}$
}

1 Mestre em Gestão Estratégica das Organizações (URI). Professor e Coordenador do Curso de Administração da URI Cerro Largo. Contato: roberto@uricl.com.br

2 Mestra em Desenvolvimento (UNIJUÍ). Professora da URI Cerro Largo. Contato: borghettiadministrativo@ via-rs.net

3 Doutor em Engenharia da Produção (UFSC). Professor da URI, Cerro Largo. Contato: edio.pk@gmail.com

4 Doutoranda em Desenvolvimento Regional (UNIJUİ). Professora da URI Cerro Largo. Contato: lucianascherer@yahoo.com.br

5 Mestrando em Gestão Estratégica das Organizações (URI). Professor e Diretor Geral da URI Cerro Largo. Contato: bolzanedson@via-rs.net 


\section{INTRODUÇÃO}

Tem sido crescente a busca de novas alternativas que corroborem o processo de sustentabilidade. Essas alternativas já existem em muitos espaços geográficos, mas geralmente não têm sido objeto de estudos mais detalhados sobre suas potencialidades e dificuldades. Este capítulo apresenta o estudo que buscou mais informações sobre o sistema cooperativista e sua contribuição com o desenvolvimento local em seu espaço de atuação. Nesse sentido, destaca-se que nas cooperativas agrícolas têm sido priorizadas as atividades que levem à organização dos agricultores, renda das famílias, aos baixos índices de poluição, à preservação das culturas e tradições locais e à manutenção das pequenas propriedades rurais.

Nesse contexto, buscou-se investigar o seguinte problema de pesquisa: qual o modelo de gestão adotado pela COOPEROQUE e como ele contribuiu com a sustentabilidade dos associados? A partir dessa problemática, o objetivo foi, portanto, analisar o modelo de gestão cooperativista adotado pela COOPEROQUE e sua contribuição com o desenvolvimento dos associados.

O cooperativismo tem se mostrado um agente propulsor no desenvolvimento das localidades onde está inserida a Cooperativa Agrícola Mixta São Roque - COOPEROQUE, que há longo período vem sendo mencionada em diversas organizações como um exemplo no meio cooperativista devido ao seu sucesso, como uma cooperativa que optou por construir uma organização que prioriza a atuação local. Esse trabalho foi reconhecido de maneira significativa no dia 03 de junho de 2013, quando a cooperativa recebeu em Novo Hamburgo (RS), no salão de eventos da FENAC, o Prêmio Mérito Empresarial Gaúcho 2013, concedido àquelas que se destacaram em 2012 no cenário estadual.

Assim se suscita a curiosidade de entender as condições segundo as quais uma cooperativa poderia desenvolver-se, se posicionando, ainda, como um importante propulsor de desenvolvimento local, de forma a poder compreender e buscar orientações para a promoção do desenvolvimento em outros contextos cooperativistas. Com base nisso, procura-se explorar as ações estratégicas empreendidas pela COOPEROQUE durante sua trajetória. 


\section{REFERÊNCIAS DE ANÁLISE}

Conforme Baldus e Willens, citados por Pinho (1966, p. 7), do ponto de vista sociológico, "cooperação é uma forma de integração social e pode ser entendida como ação conjugada em que pessoas se unem de modo formal ou informal, para alcançar o mesmo objetivo". A cooperação pressupõe, necessariamente, a liberdade de trabalhar em comunidade.

Segundo Rodrigues (2002), o cooperativismo, analisado de uma forma doutrinária, é a reunião de um conjunto dogmático de princípios que compõem a doutrina, ou, ainda, é um sistema econômico-financeiro que objetiva a transformação e consolidação social. A sociedade cooperativa é a reunião de pessoas para a realização de atividades econômicas em comum por meio de uma organização coletiva e democraticamente controlada, que busca, em conjunto e mediante objetivos comuns, a obtenção de melhorias de condições de vida e de renda dos integrantes do grupo.

Para analisar as perspectivas das organizações cooperativas é fundamentalmente necessário acompanhar os processos de gestão e as imposições impostas pelas forças externas. Empreender a gestão é contribuir para a continuidade de atuação dessas organizações no mercado. Para que isso ocorra, as organizações cooperativas devem fundamentar-se em boas práticas de gestão, direcionadas pela realização de planejamento adequados e possíveis de serem atendidas, sintonizando-se aos anseios dos seus cooperados.

Quando está em questão a profissionalização da gestão nas cooperativas, existem dois aspectos importantes: um está relacionado à profissionalização da direção da cooperativa e outro está ligado à contratação de profissionais especializados para auxiliarem no processo decisório dos dirigentes. A necessidade de profissionalização dos dirigentes das cooperativas é uma questão de sobrevivência para o futuro. As cooperativas não podem mais ser administradas por amadores, curiosos ou aprendizes em um mundo em que os negócios estão extremamente complexos (HAAS; REISDORFER, 2012).

A estratégia de uma cooperativa pode ser conceituada como um processo cuja finalidade é possibilitar o alcance da situação futura desejada pela organização. E, senão o único, mas, pelo menos, o principal instrumento utilizado nesse sentido é o planejamento estratégico, cujo desenvolvimento inclui três diferentes 
níveis de estratégias: estratégia corporativa, que se refere às decisões relativas ao negócio em que a empresa deve entrar e sair e como deve distribuir os recursos entre os diferentes negócios em que está envolvida; estratégia em nível de unidade de negócio ou estratégia competitiva, que se refere aos meios pelos quais a empresa busca vantagem competitiva em cada um desses negócios mais importantes; e estratégia funcional, que inclui as decisões, ações desenvolvidas pelas diversas áreas funcionais da empresa, tais como produção, marketing, fianças, materiais e gestão de pessoas. (ANDRADE, 2012).

\section{METODOLOGIA DA PESQUISA}

O estudo que constitui este capítulo é de natureza qualitativa, configurada em um estudo de caso, com o intuito de identificar uma estrutura cooperativista e sua contribuição com o desenvolvimento local, baseada na percepção dos atores sociais de uma cooperativa agrícola localizada em Salvador das Missões, nas Missões do Rio Grande do Sul.

Com relação aos seus objetivos, caracteriza-se como descritivo e exploratório. Descritivo, porque exige o levantamento de informações utilizando conceitos teóricos a respeito do tema, com vistas a identificar os componentes necessários para a elaboração do processo. A pesquisa descritiva tem como objetivo principal a descrição das características de determinada população ou fenômeno ou, então, o estabelecimento de relações entre as variáveis (GIL, 2002).

De acordo com Triviños (2006), independente do tipo de coleta de dados, para obtenção de resultados científicos no campo das ciências humanas e sociais, as informações devem mostrar coerência, originalidade, consistência e objetividade, em concordância com os aspectos de critérios internos de verdade e de critérios externos de intersubjetividade.

Uma das técnicas utilizadas para a coleta de dados foi a análise documental, com a qual foram avaliados estatuto e relatórios de gestão que forneceram as informações necessárias para a compreensão estrutural da cooperativa agrícola. Richardson (2008) ressalta que a análise documental "pode ser definida como a observação que tem como objeto não os fenômenos sociais, quando e como se produzem, mas as manifestações que registram estes fenômenos e as ideias elaboradas a partir deles". 
A coleta documental junto à organização é de extrema importância, pois através dela o pesquisador tem uma base de dados do estudo que está realizando. Através da autorização da empresa é possível conseguir uma visão geral e consistente da organização possibilitando que o estudo seja mais bem aprofundado (YIN, 2005).

Outra técnica utilizada para a coleta de informações foi a entrevista semiestruturada com as pessoas que participam do sistema cooperativista, como presidente, superintendente, o diretor administrativo e alguns cooperados, que foram escolhidos de forma aleatória. As entrevistas formam realizadas numa amostra diversificada com o intuito de perceber as diferentes representações sobre a COOPEROQUE e sobre a sua influência na trajetória de desenvolvimento da Vila Santa Catarina. Richardson (2008) comenta que "a entrevista é uma técnica importante que permite o desenvolvimento de uma estreita relação entre pessoas". "É o modo de comunicação no qual determinada informação e transmitida de uma pessoa A para uma pessoa B".

\section{RESULTADOS}

\section{Modelo de gestão da COOPEROQUE}

Quanto à gestão adotada pela Cooperativa, para os gestores, o modelo é tradicional, pois a estrutura da gestão é composta pelo Conselho de Administração, Conselho Fiscal e o Presidente, que são eleitos pelos associados em assembleia. Otmar Afonso Langer ocupa o cargo de presidente há 20 anos e atua na Cooperativa no dia a dia, exercendo suas funções e, quinzenalmente, reúne-se com o Conselho de Administração, responsável por contratar os profissionais para gerenciar os negócios da Cooperativa. Os profissionais contratados ocupam os cargos de Superintendente e Diretor Administrativo, e eles são responsáveis por levar os planos de curto, médio e longo prazo para o Conselho, que tem a função de analisar e discutir essas propostas e aprová-las ou não. Os gestores afirmam que na maioria das vezes as propostas são aprovadas. O cargo de $\mathrm{Su}$ perintendente é ocupado por Elmart Strake, "filho do primeiro sócio fundador, Vice-presidente e Diretor Gerente da COOPEROQUE”, que atua como colaborador da cooperativa há 53 anos e há 32 anos ocupa o cargo de Superintendente. 
A administração da cooperativa é realizada pelo Superintendente e pelo Diretor Administrativo. O Sr. Elmar Strake afirma que além das atividades rotineiras é responsável pelas grandes negociações, como a comercialização de grãos, fertilizantes, agrotóxicos e a busca de recursos financeiros, e que aos poucos está delegando algumas responsabilidades dessas atividades ao Diretor Administrativo, Sr. Mauro Resch.

Cabe ressaltar que na COOPEROQUE, quando são eleitos novos membros do Conselho Fiscal e do Conselho de Administração através da AGO, a Diretoria Executiva permanece a mesma. Segundo os dirigentes, essa é uma estratégia para dar continuidade ao desenvolvimento da cooperativa, estratégia que se incorporou à cultura da Cooperativa, pois é adotada há 62 anos. A COOPEROQUE nunca enfrentou disputa eleitoral ao longo dos seus 62 anos. A diretoria sempre foi eleita por aclamação na AGO, o que, segundo os dirigentes, "é muito bom, pois quando há disputa dentro da cooperativa isso acaba dividindo os associados, e isso não é bom".

Para os associados, o modelo de gestão adotado pela Cooperativa é bom, pois afirmam que a gestão é séria e transparente. Vários entrevistados citam qualidades profissionais do Superintendente Sr. Elmar Stracke, demonstrando que ele é referência para os associados na gestão da Cooperativa.

\section{O planejamento da Cooperativa}

Para que a Cooperativa seja conduzida por um modelo de gestão eficaz, é de fundamental importância que os gestores tenham um processo de planejamento definido. Oliveira (2011) alega que o planejamento estratégico não deve ser visto como uma previsão sobre o futuro, mas como um conjunto de ações estratégicas para eventos variados que podem, ou não, se concretizar, daí a necessidade de adaptá-lo sempre que necessário. Almeida (2001) corrobora essa ideia ao afirmar que um planejamento formal excessivamente rígido pode frustrar estratégias potenciais. O planejamento precisa ser flexível para não correr o risco de imobilizar a organização.

Sobre o processo de planejamento, os gestores da COOPEROQUE afirmam trabalhar com planejamento, pois são realizadas reuniões semanais entre a diretoria executiva (presidente e secretário) com os prepostos (superintendente e 
Diretor Administrativo), quando são discutidos, avaliados e analisados aspectos relevantes de todos os setores da Cooperativa. Nessas reuniões são propostas as ações a serem tomadas em curto, médio e longo prazo, que posteriormente são encaminhadas para análise ao Conselho de Administração. Também são realizadas reuniões mensais com os principais setores da cooperativa: Setor de Cereais, Laticínios e Indústria, onde as proposições e ações são discutidas, bem como são definidos os planos de metas.

Quando questionados sobre o planejamento em longo prazo, percebemos que ele está centrado em investimentos em construções, pois os gestores afirmam que foi iniciada uma obra de um novo escritório com duas novas balanças, para atender a necessidade do complexo de armazéns. Terminando-a, se iniciará a construção de um novo depósito para agrotóxicos e fertilizantes. Quando esse depósito estiver concluído, se iniciará a construção da agroindústria de laticínios, e após a Cooperativa já dispõe de um projeto para reestruturar todo complexo administrativo que envolve supermercado, magazine e agropecuária que será uma construção em torno de $5.000 \mathrm{~m}^{2}$. Assim os gestores afirmam ter planejamento definido para os próximos 5 anos.

\section{Participação do associado na tomada de decisão da Cooperativa e acesso à direção}

A relação da organização com os cooperados também se configura como importante fator de gestão cooperativa. Através da gestão social, se possibilita o acesso a determinados tipos de benefícios possibilitados através da Cooperativa.

Quanto à participação dos associados na tomada de decisão da cooperativa, os gestores afirmam que os associados participam através da AGO, em que, historicamente, a grande maioria dos associados participa e as principais decisões são colocadas em votação. Mas para os investimentos menores são delegados poderes para o Conselho de Administração junto aos gestores contratados. Quanto ao acesso dos associados à direção os gestores afirmam ser esse um grande diferencial da Cooperativa, pois quando o associado tem necessidade de falar com os administradores da cooperativa ele é atendido.

Sobre a participação na tomada de decisão, os associados afirmam que os assuntos mais importantes são postos em votação na AGO e nela o cooperado tem total liberdade de se manifestar para expressar sua opinião. 
Quanto ao acesso dos associados à Direção, eles afirmam que os associados têm total liberdade para procurar os gestores da cooperativa e são atendidos por eles. Cabe salientar que, segundo os associados, todos conhecem os dirigentes e todos os dirigentes conhecem o associado, o que, certamente, é um diferencial da Cooperativa.

O órgão deliberativo máximo das cooperativas, a Assembleia Geral Ordinária, acontece na Cooperativa no início do exercício, até o mês de março. Essas assembleias podem servir como verdadeiro exercício da democracia ou simplesmente como legitimadoras das decisões tomadas pelos dirigentes, dependendo do relacionamento que se estabeleça entre organização e associado, e depende do nível de envolvimento que tenha na cooperativa. Em relação às eleições, nunca houve mais que uma chapa concorrendo para a presidência da Cooperativa. $\mathrm{O}$ atual presidente ocupa o cargo desde 1993. Esse seria um ponto negativo crítico no caso desenvolvido pela COOPEROQUE, uma vez que se tem orientação na rotatividade dos cargos como parte da filosofia cooperativista. Entretanto, também não se pode afirmar que isso se constitui num problema infranqueável, desde que a manutenção dos cargos seja de consenso em assembleias.

\section{Períodos estratégicos e eventos}

Nesta fase da pesquisa identificaremos, a partir da caracterização histórica da trajetória da organização, os eventos críticos de maior relevância que possibilitaram os resultados alcançados pela COOPEROQUE. Entende-se por eventos críticos “as mudanças estratégicas de uma organização" (WBATUBA, 2004, 162). Para Sausen (2003), estudar as mudanças pressupõe, então, não apenas adotar um modelo de referência, tampouco procurar unidade e coerência entre modelos, mas, principalmente, enriquecer-se no conhecimento de suas diferenças e complementariedades. Considerar a simultaneidade de perspectivas é de fundamental importância para construir o entendimento do real significado da mudança estratégica.

Os eventos críticos levantados foram separados por períodos estratégicos. "O período estratégico é caracterizado por um conjunto de decisões que cria um padrão de comportamento estratégico caracterizado por período" (WBATUBA, 2004, 162). Assim, para período estratégico importantes faremos uma descrição de eventos críticos que caracterizaram as mudanças estratégicas processadas 
naquele período. Essa descrição foi possível a partir das entrevistas realizadas pelo pesquisador durante o trabalho de campo.

A seguir reúnem-se em duas tabelas que apresentam os períodos estratégicos que foram definidos juntamente com a alta direção da cooperativa estudada e os eventos críticos que foram definidos a partir da análise documental e das entrevistas, com seu respectivo ano ou períodos de acontecimento a serem detalhados posteriormente.

Tabela 1 - Períodos estratégicos

\begin{tabular}{l|l}
\hline Períodos Estratégicos & Descrição \\
\hline I - 1951 a 1980 & Adaptação e Identidade \\
\hline II - 1981 a 2014 & Estruturação e Consolidação \\
\hline & Fonte: Autor (2014).
\end{tabular}

Tabela 2 - Eventos críticos

\begin{tabular}{l|l}
\hline Eventos críticos & Ano \\
\hline Fundação da Cooperativa & 1951 \\
\hline Tentativa de expansão & 1959 \\
\hline Suínos a base da economia & $1951-1990$ \\
\hline Recessão & $1970-1980$ \\
\hline Implantação do repasse agrícola & 1981 \\
\hline Estruturação da Cooperativa & 1984 \\
\hline Impulso agroindustrial & 1993 \\
\hline Investimentos em construções e qualidade & 1997 \\
\hline Fomento a bacia leiteira & 2007 \\
\hline Agricultura de precisão & 2008 \\
\hline Prêmio Mérito Empresarial Gaúcho & 2013 \\
\hline
\end{tabular}

Fonte: Autor (2014).

Uma vez que a COOPEROQUE tem suas bases voltadas à gestão cooperativa, em sua essência, segundo teve seu significado já detalhado, percebe-se que os períodos não são determinados por sequência cronológica, uma vez que as ações não são limitadas, sobrepondo suas características nesta trajetória, tendo como primeira fase 1951 a 1980, e segunda fase de 1981 a 2014. A Cooperativa sempre empreendeu estratégias que iam ao encontro de dois componentes 
da gestão cooperativa (gestão empresarial e gestão social). O que lhe proporcionou desenvolvimento no sentido mais amplo por combinar ações diversas e complementares para desenvolver a organização e a localidade. A seguir serão apresentados os períodos estratégicos da Cooperativa.

Primeiro período estratégico: fase de "adaptação" e "identidade" foi voltada à constituição da COOPEROQUE. As ações empreendidas nesse período demonstraram necessidade de buscar a independência comercial. Esse período foi constituído pelos seguintes eventos críticos: fundação da cooperativa, tentativa de expansão, suínos como base da economia e a recessão.

Em $1^{\circ}$ de novembro de 1951, 33 agricultores fundaram a Cooperativa Agrícola Mixta São Roque Ltda, na comunidade hoje Vila Santa Catarina. Esses agricultores integralizaram Cr\$100.000,00 (cem mil cruzeiros), como capital inicial, sob a liderança do Professor Seno Marcos Stracke, seu primeiro gerente. O principal objetivo do grupo era a compra de insumos e venda da produção em comum, para fugir dos intermediários no comércio particular que, na época, já era forte na região.

Em 1960, a Cooperativa adota uma estratégia de expansão com a instalação de um Posto de Recebimento de Mercadorias, no município de Roque Gonzáles, que logo após foi transformado em filial. Essa ação que visava o crescimento da Cooperativa não teve sucesso e, logo em 1962, ocorre o desmembramento da filial de Roque Gonzáles. Após essa tentativa de expansão frustrada, a Cooperativa não demonstrou mais interesse em expandir com novas filiais. Os dirigentes atuais afirmam que a Cooperativa não tem intenção de crescer horizontalmente, mas, sim, verticalmente, sempre prestando mais serviços aos seus associados. A suinocultura foi a base de sustentação da cooperativa durante várias décadas. Considerada como alicerce da Cooperativa, a criação de suínos exerceu um papel de grande importância econômica para a região. Atuando nas áreas de fomento, assistência e comercialização, a Cooperativa, ao longo desses anos, sempre garantiu insumos básicos e comercialização da produção aos criadores associados que se dedicaram a essa atividade. Atividade que na década de 90 perdeu forças e foi absorvida por grandes empresas, que adotaram o sistema de integração com os produtores, sistema que hoje ainda é adotado pelo setor. Devido a essa condição de mercado, a Cooperativa se viu obrigada a buscar outras alternativas, que serão descritas nos próximos períodos. Outro fator importante 
que lembra a época foi a construção da primeira sede, em 1954, com $402 \mathrm{~m}^{2}$, que hoje ainda é utilizada e abriga parte da agropecuária da Cooperativa.

As maiores dificuldades, porém, foram sentidas na década de 70, com o surgimento das grandes cooperativas tritícolas, que com suas estruturas faraônicas foram dominando as cooperativas agrícolas mistas de pequeno porte. Nesse período, muitas dessas cooperativas foram incorporadas e outras acabaram encerrando suas operações, quando a COOPEROQUE relutou para não ser incorporada.

Apesar do período difícil enfrentado, a direção e seus associados nunca deixaram de confiar no desenvolvimento da Cooperativa, que conseguiu manter-se independente. Nesse período, percebeu-se a necessidade de mudança. Era preciso buscar um diferencial. O sistema adotado atendia as principais dificuldades dos associados, mas isso ainda não era suficiente.

Segundo período estratégico: fase de "estruturação" e "consolidação" caracterizada por ações voltadas ao crescimento da COOPEROQUE. As diversas ações empreendidas demonstraram a necessidade de articular a organização. Buscar e criar articulação e bases sólidas. Esse período foi constituído pelos seguintes eventos críticos: implantação do repasse agrícola, estruturação da Cooperativa, impulso agroindustrial, investimentos em construções e qualidade, fomento à bacia leiteira, agricultura de precisão de Prêmio Mérito Empresarial Gaúcho.

Percebendo a dificuldade que os produtores rurais enfrentavam na época em relação ao acesso aos recursos financeiros para cultivar suas lavouras, a direção buscou uma alternativa que realmente suprisse essa necessidade, implantando o repasse agrícola. Foi uma estratégia que fortaleceu a parceria entre Cooperativa e associados, marcando o início da segunda fase.

Com a implantação do repasse agrícola, a Cooperativa adotou um sistema que vinculou a venda dos insumos e o recebimento da produção do associado. Com isso, a Cooperativa passou a vender mais insumos e receber mais produção. O repasse agrícola é adotado até os dias de hoje. O agricultor não precisa procurar o banco para efetuar o seu financiamento. Ele vai até a Cooperativa, que encaminha sua proposta de financiamento para o banco, avalizando todos os financiamentos contratados neste sistema. Esse período lembra a revolução do campo pela mecanização agrícola e exploração comercial de cereais, caracterizado pelo binômio trigo e soja. 
Foi na década de 80 que a COOPEROQUE mais cresceu e se estruturou para absorver o aumento da produção proporcionada pelo sistema de repasse agrícola adotado na fase anterior. Esse período registra os investimentos: a cooperativa investiu em assistência técnica através de agrônomos e técnicos agrícolas, e essa estratégia foi fundamental para o desenvolvimento do associado, pois levou até ele conhecimento e tecnologia que refletiram no aumento da produtividade; construção de um escritório novo com $88,53 \mathrm{~m}^{2}$ na antiga sede; construção de duas moegas de descarga para cereais e balança com capacidade de $60.000 \mathrm{~kg}$; construção do armazém graneleiro com $1.250 \mathrm{~m}^{2}$ e capacidade para 120.000 sacas de cereais; instalação do secador de cereais $40 \mathrm{kwa}$ e do posto de recebimento de suínos com $377,3 \mathrm{~m}^{2}$; instalação de dois silos metálicos e moega com $619 \mathrm{~m}^{2}$, com capacidade de 60.000 sacas de cereais; construção da nova Sede Administrativa, com $1.464 \mathrm{~m}^{2}$; construção de dois silos metálicos com $390 \mathrm{~m}^{2}$ capacidade de 60.000 sacas de cereais; instalação do Supermercado e Magazine na Sede Administrativa.

O impulso agroindustrial foi marcado pela construção e instalação do moinho de trigo com capacidade de moagem de 120 mil sacas por ano e registro da patente da primeira marca Farinha Missões. O incentivo dado pela Cooperativa e a garantia de comercialização da cultura de trigo deu um novo impulso num momento em que esse e outros setores foram fortemente penalizados. A política econômica globalizada e a ausência de um plano agrícola regional praticamente inviabilizaram a cultura de trigo no Brasil.

Para o superintendente da Cooperativa, "O moinho proporcionou a nossa região a posição de região que mais planta trigo, em proporção à área, no Rio Grande do Sul. Devido a nossa política do trigo, a Cooperativa garante a comercialização, paga melhores preços pela produção, então isso beneficia toda a região onde a Cooperativa está inserida, e também para ajudar o produtor se manter na atividade, isso fortalece a comunidade e fortalece o município com o retorno do ICMS quando maior a produção primaria, mais retorno para o município de origem".

O trigo é uma cultura de inverno que, além de ser mais uma fonte de renda ao associado, também tem uma fundamental importância no ciclo de produção do agricultor, pois serve como cobertura de solo, adubando-o e, assim, beneficiando as outras culturas. 
A busca pela qualidade e investimento em construções foi marcada pelos investimentos em programa de qualidade e em construções. Trata-se de importante momento para a Cooperativa, pois seu trabalho foi reconhecido por um órgão externo. A Cooperativa aderiu ao Programa Gaúcho de Qualidade e Produtividade/RS em 1997 e, em 1999, foi congratulada com o Diploma de Distinção ao Mérito, concedido por reconhecimento às organizações que se destacaram.

Em relação às construções, fizeram-se os seguintes investimentos: instalação de mais quatro silos metálicos com capacidades de 120.000 sacas e mais duas moegas; cercado e pavimentação dos silos e armazéns área total 10.000 $\mathrm{m}^{2}$; ampliação do Supermercado em $432 \mathrm{~m}^{2}$; comemorações alusivas aos cinquenta anos de atividades; construção de garagem para caminhões junto ao moinho $\left(165 \mathrm{~m}^{2}\right)$, cobertura para estacionamento do setor de administração $(153,75$ $\left.\mathrm{m}^{2}\right)$, cobertura metálica para carga e descarga do Supermercado $\left(72 \mathrm{~m}^{2}\right)$; construção de um depósito de insumos e agrotóxicos $\left(1.265 \mathrm{~m}^{2}\right)$; pavimentação em torno do depósito $\left(3.008 \mathrm{~m}^{2}\right)$; construção de dois silos metálicos com capacidade para 100.000 sacas de grãos.

O fomento à bacia leiteira surgiu após confirmada a tendência de centralização do setor suinícola, limitado cada vez mais a poucos produtores e plantéis maiores. O setor de produção primária traça um novo panorama. Produtores que no passado faziam da suinicultura uma atividade paralela à produção de cereais, para completar a renda familiar, estão hoje se estruturando cada vez mais para a atividade leiteira e muitos deles transformaram a produção de leite como atividade principal. A Cooperativa acreditou ser esta a atividade capaz de viabilizar a pequena propriedade, evitando o abandono do campo pelo produtor. Baseada nessa tendência, elaborou um estudo técnico de viabilidade econômica, para a elaboração de um projeto de industrialização do leite e traçou metas para os anos seguintes.

Para o início do projeto, foi construída uma plataforma com capacidade para 240.000 litros/dia, para recebimento e resfriamento - e após comercialização do leit. Foram adquiridos três caminhões/tanque Mercedes Benz novos para coleta do leite e duas caminhonetes VW Saveiro para o departamento técnico.

Para o associado produtor de leite a cooperativa iniciou um projeto de assistência técnica a fim de fomentar a atividade leiteira. Esse projeto é pioneiro no estado do Rio Grande do Sul e iniciou com a participação de 40 produtores, que recebem assistência técnica gratuita. No primeiro ano da implantação, 
conseguiu-se aumentar em 100\% a produção leiteira. Além desse aumento da produção, também aumentou a qualidade. Além da assistência técnica aos associados produtores, a Cooperativa presta assistência em projetos que visem à compra de implementos, ordenhadeiras, resfriadores, assim como auxilia na busca de financiamentos com juros e condições mais acessíveis. Em 2014, ano deste estudo, o leite era comercializado com a CCGL.

A COOPEROQUE, percebendo a necessidade de aumentar a produção agrícola e adequar o produtor associado às novas tecnologias proporcionadas pelo mercado, iniciou um novo projeto - implantação da agricultura de precisão. Trata-se de tecnologia que permite uma valorização da variabilidade espacial dos atributos do solo e a possibilidade de manejá-lo, visando aumentar a eficiência técnica e econômica do uso de insumos. Para Santi (2012), a utilização do conjunto de tecnologias da agricultura de precisão deve ser vista como uma moderna técnica de gerenciamento dos atributos do solo em uma determinada área, fornecendo subsídios para o adequado aprimoramento do manejo e maximização da eficiência dos recursos produtivos, alicerçado no manejo localizado e no respeito à variabilidade existente no campo.

A Cooperativa adotou o sistema de agricultura de precisão completo. Ela disponibiliza para seus associados a coleta e análise de solo, faz o mapeamento da lavoura, disponibiliza um caminhão especial (twiter) que distribui os corretivos para o solo. Outro caminhão distribui calcário. Todos esses serviços são realizados sem custos aos associados. A Cooperativa também realizou uma parceria com Bayer Leva, com investimentos de $\mathrm{R} \$ 2.108 .000,00$ na implantação de um sistema de tratamento de sementes. Esse é um sistema inovador para proteção contra pragas e doenças que resulta em qualidade na produção de trigo, milho e soja.

Outros investimentos importantes realizados no período: instalação de sistema de climatização em todo prédio da sede; aquisição e instalação de mais um secador/cereais Joscil e tombadores de cereais para carretões e caminhões; aquisição de dois geradores de energia mais potentes; construção de casa de máquinas para gerador de energia em anexo à agropecuária; construção do depósito de tratamento de sementes em anexo à área do calcário; construção de seis silos de concreto armado com capacidade de 350.000 sacas de grãos; construção de um prédio com balança para pesagem de caminhões no setor de laticínios; aquisição de um caminhão para coleta e um silo para armazenagem de leite 
com capacidade de 50.000 litros; aquisição de um caminhão com basculante graneleiro bitrem; construção de uma moderna unidade de recebimento/armazenagem de cereais em substituição ao antigo armazém graneleiro (demolido), com tombador para carretas, novo secador, gerador, transformador, máquina de limpeza, tulhas, elevadores e sistema de captação de partículas e resíduos. Os gestores afirmam que a Cooperativa criou uma equipe própria de construção, devido às constantes obras.

Para coroar a trajetória desta Cooperativa sexagenária, no dia 03 de julho de 2013, a COOPEROQUE recebe em Novo Hamburgo (RS) o Prêmio Mérito Empresarial Gaúcho 2013, concedido às empresas que se destacaram em seu segmento em 2012, no cenário estadual. As empresas participantes são avaliadas por critérios como a condição financeira, histórico de contribuições sociais e fiscais e ação dos gestores. São também consideradas as ações regionais de apoio a questões sociais e ambientais, com destaque ao fortalecimento dos agricultores em suas propriedades.

Sobre a conquista do prêmio os gestores afirmam que ele veio coroar um trabalho que é resultado do respeito e da aplicação dos valores da cooperativa, "trabalho, credibilidade, honestidade e prudência".

\section{CONSIDERAÇÕES FINAIS}

O objetivo do estudo que constitui este capítulo foi "analisar o modelo de gestão cooperativista adotado pela COOPEROQUE e sua influência na sustentabilidade dos associados". Ele foi alcançado, pois foi analisado o modelo de gestão na Cooperativa, que é composto pelo Conselho de Administração, Presidência, Vice-Presidência, Superintendência e Direção Administrativa. O Conselho de Administração reúne-se quinzenalmente com a Diretoria Executiva para discutir as propostas apresentadas pelo superintendente e pelo diretor administrativo, que são profissionais contratados pela Cooperativa para administrá-la. As grandes negociações, como a comercialização de grãos, compra de fertilizantes e captação de recursos financeiros, estão centralizadas no superintendente, que atua há 32 anos na função e afirma estar, aos poucos, delegando alguns negócios importantes ao diretor administrativo.

Para os associados, o modelo de gestão utilizado tem sido de fundamental importância para o desenvolvimento da Cooperativa, e a maioria dos entrevistados 
elogia os gestores. Quanto à forma de planejamento utilizada, podemos observar que o método adotado é através da realização de reuniões semanais com a presença do presidente, secretário, superintendente e diretor administrativo quando são discutidos e avaliados todos os aspectos importantes relevantes a todos os setores da Cooperativa. Nessas reuniões são propostas as ações a serem tomadas em curto, médio e longo prazo. Posteriormente, muitas delas serão avaliadas pelo Conselho de Administração. Pode-se observar que o planejamento em longo prazo desenvolvido pela COOPEROQUE está basicamente relacionado a investimentos em infraestrutura.

Quanto à participação dos associados na tomada de decisão e acesso à Direção da Cooperativa, percebemos que a participação no processo de tomada de decisão se dá nas assembleias gerais ordinárias, com a participação de grande número de associados. Na ocasião, os resultados do exercício anterior e os planos futuros que requeiram investimentos maiores são apresentados pela Direção e postos em votação. Ainda sobre a participação dos associados na tomada de decisão, alguns entrevistados contestaram a maneira que a votação é conduzida, pois é utilizada a votação por aclamação e eles acreditam que os associados se sentem constrangidos a manifestar-se. Por isso, defendem que o método de votação ideal seria através do procedimento de contagem e divulgação dos votos.

Quanto ao acesso à Direção, observou-se tanto pelas declarações dos gestores como dos associados que ele é facilitado. Deve-se ressaltar que, para a gestão cooperativista, a forma de administração deve ser conjunta, com atuação mútua entre os cooperados. O desenho organizacional deve dar apoio e suporte que as pessoas necessitam para alcançar tanto os objetivos organizacionais como para obter satisfação em seu trabalho. Para auxiliar no processo de gestão, é importante que haja interação do maior número possível de associados com a diretoria da Cooperativa.

O processo de planejamento na COOPEROQUE é contemplado com planos de curto, médio e longo prazo. Porém, ele se limita a investimentos em infraestrutura, sendo de fundamental importância o desenvolvimento de um planejamento estratégico que envolva a diretoria da Cooperativa e associados. Quanto à sustentabilidade dos associados, podemos perceber que todas as estratégias adotadas convergiram para a busca de sustentabilidade dos associados. Portanto, 
para que as cooperativas promovam a sustentabilidade dos seus associados, entendido como melhoria qualitativa e quantitativa das condições de vida, caracterizado a partir das perspectivas teorias que o enfatizam como processo, nas quais os indivíduos se posicionam como sujeitos e não objetos das políticas e ações, é essencial que se realize uma gestão cooperativa eficaz, combinando a gestão empresarial com a gestão social.

\section{REFERENCIAS}

ALMEIDA, M. I. R. de. Manual de planejamento estratégico:

desenvolvimento de um plano estratégico com a utilização de planilhas Excel. São Paulo: Atlas, 2001.

ANDRADE, A. R. de. Planejamento Estratégico: formulação, implementação e controle. São Paulo: Atlas, 2012.

GIL, A. C. Como elaborar projetos de pesquisa. São Paulo: Altas, 2002. HAAS, F. R.; REISDORFER, V. K. Estudos de casos: Modelos de gestão e políticas adotadas nas cooperativas de produção e comercialização da agricultura familiar na microrregião de Cerro Largo-RS - Brasil. In: II Encontro Brasileiro de Pesquisadores em Cooperativismo. Porto Alegre, 2012.

OLIVEIRA, D. de P. R. de Manual de gestão das cooperativas: Uma abordagem prática. 5. ed. São Paulo: Atlas, 2011.

PINHO, D. B. A doutrina cooperativa nos regimes capitalista e socialista. São Paulo: PIONEIRA, 1966, p. 272.

RICHARDSON, R. J. Pesquisa social: métodos e técnicas. 3. ed. São Paulo: Atlas, 2008.

RODRIGUES, R. Cooperativismo, o rosto humano da economia. Revista SEBRAE, 2002, nov./dez., 8 p., Brasília-DF.

SAUSEN, J. O. Adaptação estratégica organizacional: o caso da Kepler Weber S/A. Ijuí: UNIJUI, 2003.

TRIVIÑOS, A. N. S. Introdução a pesquisa em ciências sociais: a pesquisa qualitativa em educação. São Paulo: Atlas, 2006.

VALADARES, J. H. Participação e poder: o comitê educativo na cooperativa agropecuária. Lavras: UFLA, 1995. 81 p. (Dissertação - Mestrado em Administração Rural). 
WBATUBA, B. R. et al. Mudança Estratégica Organizacional: Análise de um período histórico estratégico da Cooperativa Tritícola Serrana LTDA - Cotrijuí. In: Desenvolvimento em questão - Revista do programa de PósGraduação em Desenvolvimento, Gestão e Cidadania. Universidade Regional do Noroeste do Estado do Rio Grande do Sul. Ano 2, n.3, jan./jun., 2006.

YIN, R. K. Estudo de caso: planejamento e métodos. 3. ed. Porto Alegre: Bookman, 2005. 